\title{
ПРОБЛЕМА ПЕРЕДАЧИ ЗВУКОПОДРАЖАНИЯ И ЗВУКОСИМВОЛИЗМА В ПРОИЗВЕДЕНИЯХ РОАЛЬДА ДАЛЯ (НА ПРИМЕРЕ ПРОИЗВЕДЕНИЙ «ЧАРЛИ И ШОКОЛАДНАЯ ФАБРИКА» И «ЧАРЛИ И БОЛЬШОЙ СТЕКЛЯННЫЙ ЛИФТ»)
}

\section{THE PROBLEM OF TRANSLATING ONOMATOPOEIC AND SOUND-SYMBOLIC WORDS IN THE WORKS OF ROALD \\ DAHL ("CHARLIE AND THE CHOCOLATE FACTORY" AND "CHARLIE AND THE BIG GLASS ELEVATOR")}

\section{A. Sinel'nikova}

Summary: The article analyzes the English-language literary texts of British writer Roald Dahl "Charlie and the Chocolate Factory", "Charlie and the Great Glass Elevator" and compares existing translations in Russian authored by M. Baron and E. Baron ("Charlie and the chocolate factory") and M.I. Freidkin ("Charlie and the big glass Elevator") for finding the ways of translating onomatopoeic and sound-symbolic words. An attempt is made to determine what problems the translator deals with when translating sound-imaginative units from English to Russian.

Keywords: sound-imaginative vocabulary, onomatopoeia, sound symbolism, acoustic denotation, agglomerate.

\author{
Синельникова Анастасия Петровна \\ ФГБОУ ВО «Иркутский Государственный Университет» \\ sinelnikova_anastasiya@inbox.ru
}

Аннотация: В статье проводится анализ англоязычных художественных текстов британского писателя Роальда Даля «Charlie and the Chocolate Factory», «Charlie and the Great Glass Elevator» и сопоставление существующих переводов на русском языке за авторством М. Барон и Е. Барон («Чарли и шоколадная фабрика») и М.И. Фрейдкина («Чарли и большой стеклянный лифт») на предмет способов передачи звукоподражательных и звукосимволических единиц. Предпринимается попытка установить с какими проблемами сталкивается переводчик при переводе звукоизобразительной лексики с английского языка на русский.

Ключевые слова: звукоизобразительная лексика, звукоподражание, звукосимволизм, акустический денотат, агломерат.
K расота языка вытекает из его звуков, которые в определенных условиях способны вызывать разные образы и передавать определенное душевное состояние. Подобно картине, изображающей зрительный образ предмета, язык воссоздает его слуховой образ. По словам Германа Пауля, «осознавая окружающее, человек выделяет в нем не находящиеся в покое и безмолвные предметы, а предметы, движущиеся и звучащие» [6].

Понятие звукоизобразительности является универсальным для всех языков и обусловлено их развитием. Однако в языках разных народов у звукоизобразительных единиц существуют отличия, иногда весьма значительные.

Звукоизобразительность объединяет в себе два понятия: звукоподражание (или ономатопея) и звукосимволизм (или фоносемантика) [3]. Различие этих языковых явлений, главным образом, выражено в денотате рассматриваемых единиц.

Так, у звукоподражаний (имитация звуков окружа- ющей действительности средствами языка) денотат акустический, поэтому они стремятся как можно ближе передать звуки живой и неживой природы, например, «nлюх», «мяу», «ж-ж-ж», «ква-ква» [5]. При этом звукоподражание не может стать идентичным естественному звуку, поскольку эти явления принадлежат к разным системам и играют в них разную роль. В свою очередь звукосимволизмы (наличие непроизвольной связи между звучанием и значением слова) имеют неакустический денотат, и их значение является результатом ассоциативной мысленной переработки фонетического материала, например, звук [i] часто вызывает представление о чемто «маленьком, грациозном», например, франц. petit «малый», англ. miniature - «миниатюра» [7].

В художественных текстах писатели часто используют звукоизобразительную лексику, которая служит для усиления психоакустического фона описываемой сцены, для выражения состояния героев произведения и передачи их ощущений. Появление звукоподражаний и звукосимволизмов в тексте художественного произведения не случайно, почти всегда за их использованием стоит 
авторское намерение вызвать ту или иную реакцию у читателя. Именно поэтому передача этих единиц в языке перевода крайне важна для сохранения художественной выразительности произведения и авторского замысла.

Звукоизобразительная лексика вызывает определенные трудности при переводе, так как перед переводчиком стоит сложная задача передать значение психоакустического денотата, не нарушив при этом семантическую и фонетическую структуру текста оригинала.

Рассматривая подходы разных авторов, занимающихся проблемой перевода звукоподражательной лексики, важно отметить, что при выборе эквивалента, соответствующего цели коммуникации в языке перевода, необходимо учитывать не только семантику звукоподражания, но и стиль повествования, и образность выражения [8]. Именно поэтому в художественном переводе неизбежно возникновение некоторых сложностей и расхождений с текстом оригинала.

Филолог В.В. Фатюхин, проводя общий обзор способов передачи звукоподражаний в переводе художественной литературы, отмечает, что стратегия, в основном, строится на подборе функционального аналога, или на применении переводческих трансформаций, таких как генерализация, конкретизация, добавление и опущение, компенсация, а также замены, антонимический перевод, перестановки [9].

Очевидно, чем ближе язык оригинала и язык перевода в этимологическом плане, тем проще подобрать звукоизобразительный эквивалент. В противном случае процесс перевода становится настоящей работой художника по созданию практически самостоятельного произведения.

Далее будут рассмотрены способы, к которым прибегают переводчики, чтобы решить проблему перевода звукоподражаний и звукосимволизмов в произведениях Р. Даля, которые помогают создать различные художественные образы, погружая читателя в мир звуков.

Для уточнения звукоизобразительного статуса и значения английских и русских звукоизобразительных единиц были использованы онлайн-версии словарей: «Англо-русский словарь» В.К. Мюллера [1], «Большой толковый словарь русского языка» Д.Н. Ушакова [2], «The dictionary by Merriam-Webster» [17] и «Cambridge Dictionary» [13]. Также проводился этимологический анализ материала с помощью электронного словаря «Online Etymology Dictionary» [14]. Для попытки интерпретации звукового ряда произведений был применен метод фоносемантического анализа, учитывающий ассоциативное значение отдельных фонем, их сочетание и положение в тексте.
Наиболее часто звукоподражательные и звукосимволические слова используются в художественном произведении для косвенной характеристики персонажа и его эмоционального состояния в той или иной ситуации. При переводе ключевым моментом становится способность образного слова передавать эмоциональное состояние человека или животного, особенности поведения или манеру речи. Рассмотрим следующий пример:

\begin{tabular}{|c|c}
\hline Оригинал R. Dahl & Перевод М. Барон и Е. Барон
\end{tabular}

Suddenly, the air was filled with screams of excitement. The screams came from Veruca Salt. She was pointing frantically to the other side of the river. 'Look! Look over there!' she screamed [15].

В рассказе «Чарли и шоколадная фабрика» есть персонаж Верука Солт - эта избалованная девочка привыкла, чтобы все ее требования немедленно исполнялись. Чтобы подчеркнуть характер героя, автор использует в ее репликах звукосимволический глагол «вопить» - «to scream» (звукосимволичный комплекс scr- обозначает «резкий удар или звук», вокализм типа і [skri:m] выражает звук высокого тона), который является своеобразным способом привлечения к себе внимания. В данном случае глагол выполняет функцию косвенной характеристики персонажа, которая, выражается не столько в употреблении конкретных глаголов, сколько в их обилии, и это необходимо учитывать при выборе варианта перевода.

Согласно «The dictionary by Merriam-Webster», глагол «to scream» имеет следующее значение «to produce harsh high tones» [17]. Переводчики используют глаголы «визжать», «вопить» и словосочетание «пронзительный визг», имеющие звукосимволическое происхождение. Согласно толковому словарю Д. Н. Ушакова, глагол «визжать» означает «кричать визгливо», а глагол «вопить»«кричать громко и протяжно» [2]. Таким образом, можно сделать вывод, что данный вариант перевода является эквивалентным. Рассмотрим аналогичный пример:

\begin{tabular}{|l|l|}
\hline \multicolumn{1}{|c|}{ Оригинал R. Dahl } & \multicolumn{1}{|l|}{ Перевод М. Барон и Е. Барон } \\
\hline $\begin{array}{l}\text { Mrs. Salt opened her huge red } \\
\text { mouth and started to scream [15]. }\end{array}$ & $\begin{array}{l}\text { Миссис Солт открыла рот и взвыла, } \\
\text { как пожарная сирена [12]. }\end{array}$ \\
\hline
\end{tabular}

Большое значение для языка художественной литературы имеют экспрессивные языковые формы, такие как метафоры, сравнения, метонимии, передающие эмоциональное состояние персонажа или повествователя. Чтобы передать весь смысл, заложенный в английском звукоизобразительном слове, переводчики воспользовались методом описательного перевода. Они использовали звукосимволизм в сочетании со сравнением - «взвыла, как пожарная сирена», которое является более выразительной единицей, чем глагол «to scream». Таким образом, глагол «взвыла» становится смысловым 
центром высказывания и привлекает внимание читателя. Переводчики сумели подобрать подходящий эквивалент, отражающий психоакустическую структуру денотата, который одновременно передает лексическое значение языка оригинала. Именно поэтому такой вариант перевода можно считать эквивалентным.

Другим героем сказки «Чарли и шоколадная фабрика» является мальчик Август. Для его описания автор использует звукосимволическое прилагательное «flabby», которое выступает как средство субъективного выражения отношения автора. Согласно исследованиям американского лингвиста М. Магнуса, большинство слов, содержащих сочетание редуплицированного согласного в сочетании с гласным среднего ряда в средней позиции чаще всего, имеет значение покачивания. Рассмотрим следующий пример:

\begin{tabular}{|l|l|}
\hline \multicolumn{1}{|c|}{ Оригинал R. Dahl } & \multicolumn{1}{|c|}{ Перевод М. Барон и Е. Барон } \\
\hline $\begin{array}{l}\text { Great flabby folds of fat bulged out } \\
\text { from every part of his body... [15]. }\end{array}$ & $\begin{array}{l}\text { Он сплошь был в жирных } \\
\text { складках, а лицо напоминало } \\
\text { большущий шар из теста... [12]. }\end{array}$ \\
\hline
\end{tabular}

Согласно «The dictionary by Merriam-Webster», «flabby» означает «covered with soft, loose fat; fat» [17]. B англо-русском словаре В. К. Мюллера оно переводится как «дряблый, обрюзгший» [1]. Переводчики не подобрали подходящего эквивалента, содержащего звукосимволичный компонент, и предпочли его опустить. При этом они никак не компенсировали эту потерю. Таким образом, перевод данного предложения является неэквивалентным, но адекватным, потому как передает основной смысл, заложенный в тексте, с минимальными потерями.

В следующем примере звукоподражательный глагол «to croak» - «to make a harsh, low sound, like the sound a frog makes» [13], который в данном контексте употребляется для введения прямой речи и увеличивает экспрессивность и красочность текста, в переводе был заменен менее эмоционально окрашенным «проворчать»:

\begin{tabular}{|l|l|}
\hline \multicolumn{1}{|c|}{ Оригинал R. Dahl } & \multicolumn{1}{|c|}{ Перевод М. И. Фрейдкина } \\
\hline $\begin{array}{l}\text { 'What in the world keeps this } \\
\text { crazy thing up in the air?' croaked }\end{array}$ & $\begin{array}{l}\text { Хотела бы я знать, как эта дурац- } \\
\text { Grandma Josephine [16]. }\end{array}$ \\
& $\begin{array}{l}\text { кая штука держится в воздухе! } \\
\text { фироворчала бабушка Джозе- } \\
\text { фина [11. }\end{array}$ \\
\hline
\end{tabular}

Звукоизобразительность ономатопа «to croak» была потеряна в результате подбора синонима не звукоподражательной природы. Переводчик применил метод контекстуальной замены, что сказалось как на качестве, так и на глубине текста перевода. Таким образом, выбирая лексическое соответствие, необходимо учитывать эмоциональную и стилистическую окраску исходного слова, сохраняя его оценочный, экспрессивный и эмоциональный компоненты. Рассмотрим аналогичный пример:

\begin{tabular}{|l|l|}
\hline \multicolumn{1}{|c|}{ Оригинал R. Dahl } & \multicolumn{1}{|c|}{ Перевод М. Барон и Е. Барон } \\
\hline $\begin{array}{l}\text { 'Get up, get up!' cried Mr. Wonka, } \\
\text { roaring with laughter [15]. }\end{array}$ & $\begin{array}{l}\text { Вставайте, вставайте! - Сквозь смех } \\
\text { воскликнул мистер Вонка [12]. }\end{array}$ \\
\hline
\end{tabular}

Причиной несоответствия значений звукоподражания «to roar» - «to make a very loud, deep sound» и глагола «воскликнуть» послужило желание переводчиков эмоционально не перегружать отрывок текста излишним употреблением звукоподражательных элементов с негативной коннотацией, так как переводимый текст нацелен на детскую аудиторию. Чтобы не употреблять глагол «to roar», который в русском языке имеет значение «кричать, реветь, орать» [1], переводчики заменили его на менее стилистически окрашенный ситуативный синоним «восклицать» - «сказать громко, с чувством» [2]. Они использовали метод лексической замены, но не сохранили звукоизобразительную структуру слова. Таким образом, можно сделать вывод о потере коннотативного компонента, который очень ярко выражен в английском варианте.

В процессе анализа было выявлено гораздо меньше случаев, когда английское звукоизобразительное слово заменялось нейтральной лексической единицей. Приведем следующий пример:

\begin{tabular}{|l|l|}
\hline \multicolumn{1}{|c|}{ Оригинал R. Dahl } & Перевод М. Барон и Е. Барон \\
\hline 'Whips!' cried Veruca Salt. 'What on & Борода? - выкрикнула Верука \\
earth do you use whips for?' - 'For & Солт. - Боже мой! Кому нужна бо- \\
whipping cream, of course,'said Mr. & рода? - Вам, мисс, борода была \\
Wonka. 'How can you whip cream & бы очень к лицу, - сказал мистер \\
without whips? Whipped cream & Вонка, - но, к сожалению, ириски \\
isn't whipped cream at all unless it's & еще не вполне готовы... [12]. \\
been whipped with whips.' [15]. & \\
\hline
\end{tabular}

Для того чтобы перейти к анализу звукоподражательных единиц, необходимо проанализировать эпизод в целом. Во время экскурсии по шоколадной фабрике, проходя мимо комнаты, на которой висела табличка «Хлысты всех форм и размеров» («WHIPS ALL SHAPES AND SIZES»), Верука Солт спросила Вилли Вонка, для чего они их используют. Далее последовало объяснение.

Использование звукоподражательного слова «whip» в роли существительного и глагола должно было создать юмористический эффект. Однако стилистический прием игры слов, другими словами, каламбур, не был передан на языке перевода. В русском языке не нашлось подходящего звукоподражательного слова для адекватного перевода английского «whip/to whip» - «instrument consisting usually of a handle and lash forming a flexible rod that is used for whipping; to beat with a whip or similar instrument to mix cream, etc.; very quickly until it becomes stiff» [17]. 
В данном случае полная передача смысла оказалась невозможной, что, безусловно, потребовало компенсации при переводе других моментов текста. Переводчики, не подобрав подходящего эквивалента, содержащего акустический денотат, применили метод контекстуальной замены, переведя слово более подходящим контекстным синонимом «борода», так как до этого речь шла о производстве «волосатых ирисок».

Чтобы сохранить экспрессивность и образность текста оригинала, в переводе необходимо стремиться к употреблению различных стилистических приемов, при этом оригинальный образ может быть заменен подходящим по смыслу выражением или словом. Рассмотрим следующий пример:

\begin{tabular}{|l|l|}
\hline \multicolumn{1}{|c|}{ Оригинал R. Dahl } & \multicolumn{1}{|c|}{ Перевод М. Барон и Е. Барон } \\
\hline Over she toppled, into the hole head & Миссис Солт полетела в трубу голо- \\
first, screeching like a parrot [15]. & $\begin{array}{l}\text { вой вниз, визжа как поросенок } \\
\text { [12]. }\end{array}$ \\
\hline
\end{tabular}

Согласно «The dictionary by Merriam-Webster», звукоподражание «to screech», в котором представлен звукосимволичный комплекс scr- - «резкий звук» и вокализм типа i [skri:t] - звук высокого тона, означает «to utter a high shrill piercing cry» [17] или в переводе на русский «пронзительно кричать, визжать» [1]. В языке оригинала звукоподражание «to screech» было использовано в сочетании с существительным «а parrot» - «попугай», с которым оно образовывает сравнение. Это сравнение подчеркивает характер и манеру произносимых слов, сказанных несколько раз за то время, которое Миссис Солт летела вниз по трубе. В языке перевода «а parrot» был заменен на слово «поросенок», являющееся внешней характеристикой говорящего и более привычным сравнением для русскоязычного читателя. Так, переводчики сумели подобрать звукоподражательный эквивалент, тем самым отразив не только психоакустический денотат, но и лексическое значение слова.

Рассмотрим аналогичный пример:

\begin{tabular}{|l|l|}
\hline \multicolumn{1}{|c|}{ Оригинал R. Dahl } & \multicolumn{1}{|c|}{ Перевод М. И. Фрейдкина } \\
\hline $\begin{array}{l}\text { Soon these dirty beasts will start } \\
\text { popping like popcorn! [16]. }\end{array}$ & $\begin{array}{l}\text { И скоро эти гнусные твари затре- } \\
\text { щат у меня, как сало на сково- } \\
\text { родке! [11]. }\end{array}$ \\
\hline
\end{tabular}

Перевод данного предложения был продиктован лингвокультурологическими особенностями. Так, попкорн изготавливался тысячелетиями древними индейцами Америки и превратился, в своего рода, национальное блюдо. Для реципиента подобное сравнение будет понятно, но не произведет должного впечатления. Однако все меняется, когда в текст вводится привычный образ сала на сковородке.

Переводчик, использовав метод лексической замены, передал смысл выражения и сумел сохранить звукоизобразительную структуру слова: звукоподражательный глагол «to pop» - «to make a short explosive sound» [17], в котором согласный звук [р] после краткого гласного имитирует резкое движение, переводится как «хлопать, выстреливать, трескаться» [1]. Исходя из этого, можно сделать вывод, что данный перевод является эквивалентным, так как переводчик сумел подобрать звукоизобразительный эквивалент, тем самым отразив не только психоакустический денотат, но и лексическое значение слова.

Особый интерес представляет перевод «агломератов звукоподражательных единиц» [4]. Лингвист Л.А. Горохова определяет этот термин как скопление звукоподражательных единиц в относительно небольшом фрагменте текста, объединенном общей мыслью. Использование данного термина представляется возможным и для описания скоплений звукоизобразительных единиц в целом, включая звукосимволические образования. Все агломераты можно разделить на гомогенные (с одинаковой основой/корнем) и гетерогенные. Для иллюстрации гетерогенных агломератов приведем следующий примep:

\begin{tabular}{|l|l|}
\hline \multicolumn{1}{|c|}{ Оригинал R. Dahl } & \multicolumn{1}{|c|}{ Перевод М. Барон и Е. Барон } \\
\hline All about him back metal pots were & Повсюду на гигантских плитах \\
boiling and bubbling in huge & кипели и бурлили огромные \\
stoves, and kettles were hissing & металлические котлы, свистели \\
and pans were sizzling, and strange & чайники, шипели сковородки, \\
iron machines were clanking and & стучали и лязгали странные \\
spluttering, and there were pipes & железные машины, по потолку и \\
running all over the ceiling and & стенам тянулось множество труб, \\
walls, and the whole place was & и все помещение было наполнено \\
filled with smoke and stream and & дымом, паром и какими-то дико- \\
delicious rich smells [15]. & винными ароматами [12]. \\
\hline
\end{tabular}

Агломерат включает в себя пять лексем: «bubbling», «hissing», «sizzling», «clanking», «spluttering». Описание шоколадной фабрики напоминает разные виды шума и грохота. Эти мотивы слиты с фонемным рисунком, который представлен зеркальной симметрией начального и конечного звукосимволизмов («bubbling» и «spluttering») и проявляется в редупликации согласного в сочетании с гласным заднего ряда. Эти агломераты были переведены довольно близко к тексту, при этом их количественный состав остался неизменным. Так, переводчики подобрали словарные соответствия, сохраняя психоакустические компоненты каждого значения. Сохранение краткости и лаконичности форм звукоизобразительных единиц, с помощью которых достигается синтаксический параллелизм, присутствующий в оригинале, помогает не снижать динамику повествования.

Зачастую переводчик не сохраняет неоднородность/однородность звукоизобразительных единиц, внося порой нежелательные изменения в переводи- 
мый текст.

Рассмотрим следующий пример:

\begin{tabular}{|l|l|}
\hline \multicolumn{1}{|c|}{ Оригинал R. Dahl } & \multicolumn{1}{|l|}{ Перевод М. Барон и Е. Барон } \\
\hline What is more, there was a & Мало того, посередине реки был \\
tremendous waterfall halfway along & огромный водопад - отвесная \\
the river - a steep cliff over which & скала, с которой вода падала \\
the water curled and rolled in a & плотной стеной, а затем, пенясь \\
solid sheet, and then went crashing & и бурля, разлеталась на тысячи \\
down into a boiling churning & мелких брызг [12]. \\
whirlpool of froth and spray [15]. & \\
\hline
\end{tabular}

Переводчики упустили несколько звукосимволических слов («curled» и «crashing») в языке перевода, не подобрав подходящего эквивалента содержащего звукоизобразительный денотат, что существенно сказалось на звуковом рисунке фрагмента текста и на том смысловом и акустическом образе, который создавался изначально. Следовательно, перевод данного предложения является неэквивалентным, но адекватным, потому как передает основной смысл, заложенный в тексте, с минимальными потерями. Рассмотрим еще один пример:

\begin{tabular}{|l|l|}
\hline \multicolumn{1}{|c|}{ Оригинал R. Dahl } & \multicolumn{1}{|c|}{ Перевод М. И. Фрейдкина } \\
\hline everybody clutched hold of & Путешественники в испуге уцепи- \\
machine gathered speed, the & могучая машина постепенно на- \\
rushing whooshing sound of & бирала скорость, и свист ветра \\
the wind outside grew louder and & снаружи становился все громче \\
louder and shriller and shriller & и пронзительней, пока не пере- \\
until it became a piercing shriek & шел в непрерывный оглушитель- \\
and you had to yell to make yourself & ный рев [11]. \\
heard [16]. & \\
\hline
\end{tabular}

При передаче гетерогенного агломерата «rushing whooshing», состоящего из звукосимволизма «to rush», который относится к группе слов, описывающих звук с помощью акустической ассоциации (комплекс -ash обозначает «короткое, сильное движение»), и звукоподражания «to whoosh» - «to move very quickly with the sound of air or water rushing» [17], переводчик объединил входящие в него единицы. Он использовал метод генерализации и перевел агломерат звукоподражанием «свист». Выбор слова «свист» объясняется тем, что такое явление, как «rushing whooshing sound» можно передать одним конкретным понятием с широким обобщающим значением.

Таким образом, использование гетерогенных агломератов помогает избежать нежелательных повторов одного и того же звукоизобразительного слова. Делая язык художественного произведения разнообразным, они создают наиболее полную картину описываемой акустической ситуации, выражают нюансы художественных образов, создаваемых писателем, и усиливают эстетическую значимость текста.

Приведем пример гомогенного агломерата:

\section{Оригинал R. Dahl}

Veruca struggled furiously, but the squirrels held her tight and she couldn't move. The squirrel on her shoulder went tap-tap-tapping the side of her head with his knuckles [15].

Звукоподражательный глагол «to tap» - «to hit somebody/something quickly and lightly» [17] имеет в своем составе взрывной звук [р] с предшествующим кратким гласным, которые предполагают «короткое, резкое движение». Согласно англо-русскому словарю В. К. Мюллера, глагол «tо tар» переводится «стучать, постукивать, обстукивать» [1]. Повторное произнесение одного и того же слова выражает усиленное действие. Переводчики применили метод описательного перевода, чтобы передать смысл, заложенный в английском звукоподражательном глаголе. Причиной этому можно назвать нежелание создавать в тексте тавтологии, учитывая тот факт, что русский язык имеет весьма богатый и разнообразный словарный запас. Рассмотрим еще один пример:

\begin{tabular}{|c|c|}
\hline Оригинал R. Dahl & Перевод М. Барон и Е. Барон \\
\hline $\begin{array}{l}\text { Mr. Wonka turned around and } \\
\text { clicked his fingers sharply, click, } \\
\text { click, click, three times [15]. }\end{array}$ & $\begin{array}{l}\text { Мистер Вонка повернулся, громко } \\
\text { щелкнул пальцами - раз, два, } \\
\text { три! - и в тот же миг, откуда ни } \\
\text { возьмись, перед ним появился } \\
\text { умпа-лумпа [12]. }\end{array}$ \\
\hline
\end{tabular}

Звукоподражание «to click» - «to make or cause something to make a short sharp sound» [17] создает слуховой образ. Кажется, что слышишь щелканье механизма (краткость гласного связана с обозначением резких звуков). Впечатление, производимое новыми словами «раз, два, три», отличается. В первом случае переводчики прибегают к использованию собственно звукоподражания «щелкнуть» - «производить хлопучий звук» [2]. Использование числительных «раз, два, три», у которых отсутствует звукоподражательная мотивация, для передачи комплекса «click, click, click» лишает этот фрагмент предложения ключевой роли, которую он играет в тексте оригинала. Для читателя издаваемые звуки уже не являются смысловым центром высказывания, а становятся лишь одной из деталей описания.

Фонетические средства в художественных текстах могут также выражаться графически, то есть при помощи знаков препинания или выделения слов курсивом для привлечения внимания читателя. Звуковые эффекты часто отражаются с помощью специфического написания слов, а также посредством употребления определенных шрифтов. Например, сила звука передается с помощью заглавных букв, округленный шрифт иллюстрирует мягкий, хлопающий звук, шрифт с угловатыми буквами обо- 
значает более резкий звук [10].

Так, например, звукоподражание «CRASH!», воспроизводящее механический шум и акустически напоминающее шум тормозящего автомобиля, создает пространство звука, которое помогает реципиенту ощутить многомерность повествования. В связи с тем, что уровень звука поднимается посредством восклицания, автор делает акцент на резкости движения и, как следствие, напряженности действий персонажей:

\begin{tabular}{|l|l|}
\hline \multicolumn{1}{|c|}{ Оригинал R. Dahl } & \multicolumn{1}{|l|}{ Перевод М. Барон и Е. Барон } \\
\hline Then suddenly, CRASH! - and & И вдруг - БА-БАХ! - раздался \\
the most tremendous noise of & страшный треск и грохот, будто \\
splintering wood and broken tiles & что-то обрушилось у них над голо- \\
came from directly above their & вами [12]. \\
heads... [15] & \\
\hline
\end{tabular}

B переводе слову «CRASH» соответствует междометие «БА-БАХ», значение которого совпадает с исходным звукоподражательным словом: «низкий и сильный отрывистый звук» [2]. При этом вполне стандартное междометие сопровождается глаголом «раздался», который дает более точное представление о характере звука и производимом движении. Рассмотрим еще один пример:

\begin{tabular}{|l|l|}
\multicolumn{1}{|c|}{ Оригинал R. Dahl } & \multicolumn{1}{|c|}{ Перевод М. И. Фрейдкина } \\
\hline $\begin{array}{l}\text { 'The moment the medicine is } \\
\text { swallowed - ping! - and it all } \\
\text { happens!'[16] }\end{array}$ & $\begin{array}{l}\text { Ке повит», а - раз! - и готово! Как } \\
\text { молния! [11] }\end{array}$ \\
\hline
\end{tabular}

Здесь представлена комбинация звукоподражательного слова «ping» с восклицательным знаком и тире с обеих сторон. Такое использование служит яркой иллюстрацией пунктуационного оформления резкого звука или неожиданного действия. Переводчик предпочел упустить звукоподражание «ping» - «a sharp sound like that of a striking bullet» [17], не подобрав подходящего эквивалента содержащего звукоизобразительный денотат.

Рассмотрев основные особенности перевода звукоизобразительной лексики англоязычных художественных произведений на русский язык, можно сделать вывод, что качество перевода текста, содержащего звукоподражательные и звукосимволические единицы, напрямую зависит от того, насколько глубоко переводчик пытается передать их значение. Эффективность перевода звукоизобразительных слов основана на передаче психоакустического компонента и выборе в пользу наиболее яркого звукоизобразительного слова в языке перевода.

В процессе анализа было выяснено, что при переводе звукоподражаний и звукосимволизмов, переводчики, как правило, подбирали эквиваленты для той или иной единицы. Иногда переводчики прибегали к таким способам перевода, как опущение, добавление, описательный перевод, чтобы наиболее полно передать все оттенки значения слова, которое было использовано в оригинале. При этом ни один способ перевода подобных единиц не может быть универсальным. Переводя звукоизобразительные единицы, необходимо отталкиваться от контекста и ее значения, чтобы не потерять усиленного эффекта и сохранить фоносемантический рисунок, который создал автор.

Использование звукоизобразительных единиц помогает автору сказать больше, чем говорит прямой смысл слов. Оно задействует и мысли, и воображение, и чувства читателя. Звукоизобразительные слова используются как экспрессивно-стилистическое средство отображения действительности для украшения речи, придания ей живости и красочности, что должно быть полноценно отображено переводчиком в его варианте перевода.

\section{ЛИТЕРАТУРА}

1. Англо-русский словарь В.К. Мюллера [Электронный ресурс]. - URL: https://gufo.me/dict/enru_muller (дата обращения: 20.04.2020).

2. Большой толковый словарь русского языка Д.Н. Ушакова [Электронный ресурс]. - URL: https://ushakovdictionary.ru/ (дата 0бращения: 20.04.2020).

3. Воронин С.В. Фоносемантические идеи в зарубежном языкознании: Очерки и извлечения / С.В. Воронин. - Л.: Изд-во Ленинградского университета, 1990. - $200 \mathrm{C}$.

4. Горохова Л.А. Семантико-прагматические и социолингвистические особенности функционирования ономатопов в текстах современного английского языка: Дис. ... канд. филол. наук: 10.02.21 / Л.А. Горохова. - Пятигорск, 1998. - 220 с.

5. Звукоподражания в русском и английском языках [Электронный ресурс]. - URL: http://www.hintfox.com/article/zvykopodrazhanija-v-rysskom-ianglijskom-jazikah.html (дата обращения: 15.04.2020).

6. Пауль Г. Принципы истории языка / Г. Пауль. - М.: Изд-во иностранной литературы, 1960. - 508 с.

7. Пизани В. Этимология / В. Пизани. - М.: Изд-во иностранной литературы, 1956. - 188 с.

8. Реформатский А.А. Введение в языковедение / А.А. Реформатский. - М.: Просвещение, 1996. - 536 с.

9. Фатюхин В.В. Особенности перевода звукоподражаний и междометных глаголов: на материале русского и английского языков: Дис. ... канд. филол. наук: 10.02.20 / В. В. Фатюхин. - Москва, 2000. - 184 с.

10. Фененко Н.А. «Астерикс» в России: трудности лингвоэтнической ретрансляции / Н.А. Фененко // Вестник ВГУ, Серия «Лингвистика и межкультурная коммуникация». - 2004. - № $1-$ С. 66-70. 
11. Чарли и большой стеклянный лифт [Электронный ресурc]. - URL: https://knijky.ru/books/charli-i-bolshoy-steklyannyy-lift (дата обращения: 20.04.2020).

12. Чарли и шоколадная фабрика [Электронный ресурc]. - URL: https://gigabaza.ru/doc/136170.html (дата обращения: 20.04.2020).

13. Cambridge Dictionary [Электронный ресурс]. - URL: https://dictionary.cambridge.org/ru/ (дата обращения: 20.04.2020).

14. Online Etymology Dictionary [Электронный ресурc]. - URL: https://www.etymonline.com/ (дата обращения: 20.04.2020).

15. Roald Dahl. Charlie and the Chocolate Factory. - L.: PUFFIN B00KS, 2013. - 180 p.

16. Roald Dahl. Charlie and the Great Glass Elevator. - L.: PUFFIN BOOKS, 2013. - 182 p.

17. The dictionary by Merriam-Webster [Электронный ресурc]. - URL: https://www.merriam-webster.com/ (дата обращения: 20.04.2020).

(с Синельникова Анастасия Петровна (sinelnikova_anastasiya@inbox.ru).

Журнал «Современная наука: актуальные проблемы теории и практики»

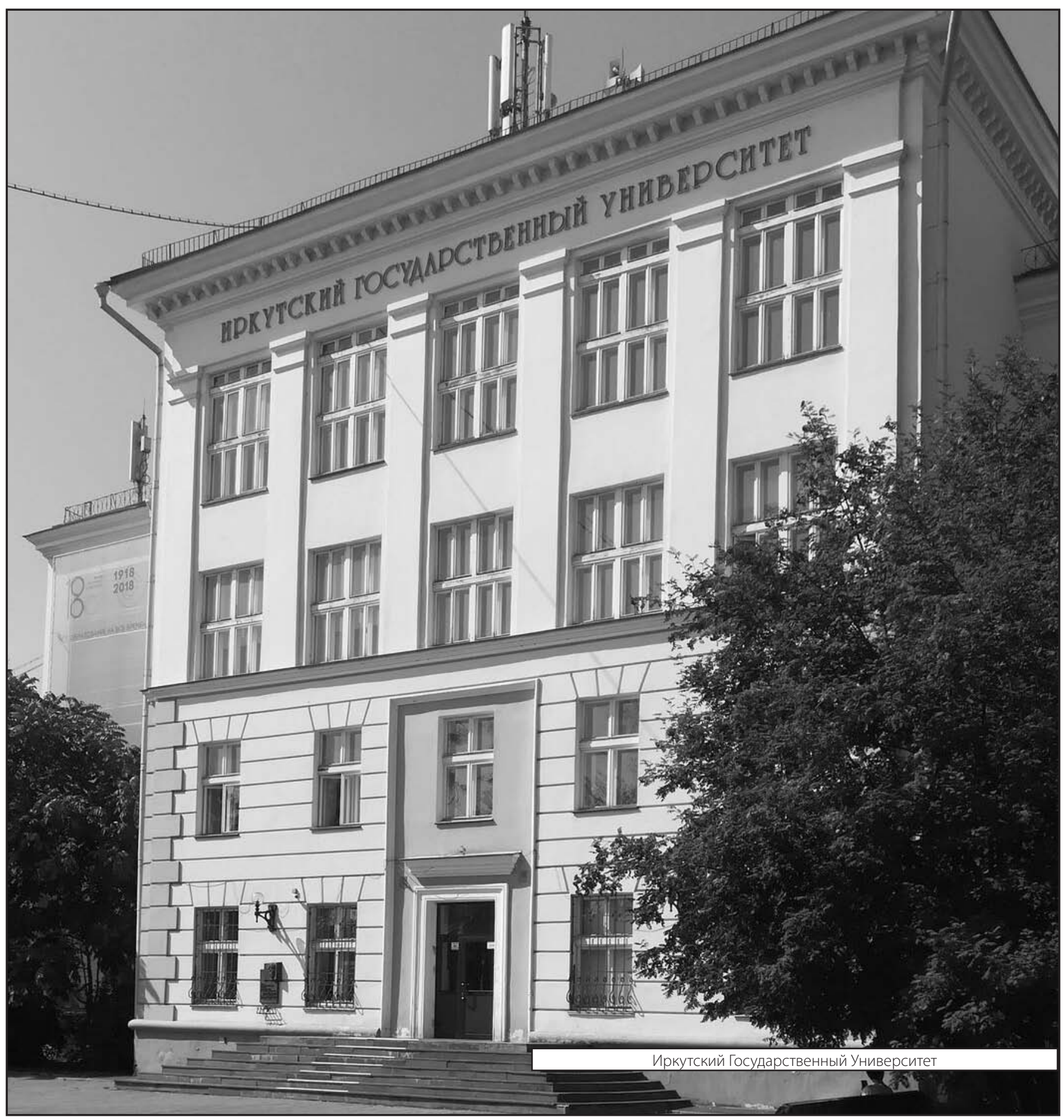

